\title{
Comment on the Central Drug Authority's position statement on cannabis
}

The Central Drug Authority (CDA)'s 'Position statement on cannabis $^{\text {[1] }}$ is a welcome, if somewhat belated, article that gives an indication of the South African (SA) government's response to the shifting sands of local and international public opinion and global drug policies. Most of the policies outlined in this document can be found in the CDA's National Drug Master Plan (NDMP) ${ }^{[2]}$ This article appears to be an attempt to clarify some of those policies, emphasise others and introduce one or two new strategies. Although the title of the paper points to a focus on cannabis, the CDA correctly ties in cannabis issues with those of alcohol, tobacco and other illicit psychoactive substances.

\section{Decriminalisation of cannabis}

The most important new policy to appear in the position statement ${ }^{[1]}$ is a recommendation for the decriminalisation of cannabis. This represents a major shift in government thinking, as the proposed decriminalisation of cannabis or any other drug does not appear in the NDMP $\left(2013\right.$ - 2017), ${ }^{[2]}$ and it is something that the CDA has previously opposed.

\section{Medical marijuana}

Unfortunately, the CDA continues to use stale arguments such as the dangers of cannabis to oppose its use as a medicinal herb. As we know, all medicines, including potentially lethal over-the-counter drugs such as aspirin and paracetamol, have many undesirable effects. Cannabis is no exception, but it is far less harmful than the above two drugs. It is also far less toxic than alcohol, which is associated with many kinds of cancer, cardiovascular disease, and other diseases. ${ }^{[3,4]}$ Alcohol is directly responsible for the deaths of over three million people annually, ${ }^{[5]}$ while deaths attributed to cannabis are insignificant in comparison. ${ }^{[6]}$ The CDA continues to justify the illegal status of cannabis and other drugs by using confirmation bias in its selective presentation of evidence to oppose the legalisation of medical marijuana. ${ }^{[7]}$ If it used the same standards regarding alcohol and tobacco, those two drugs would also be banned.

Ironically, if the CDA's recommendation for the decriminalisation of cannabis does bear fruit, individuals will be able to legally self-medicate with this herb even if the failure to legalise medical marijuana does not allow doctors to prescribe it. An unintentional, illogical policy clash?

As the CDA recommends cannabis decriminalisation rather than legalisation (cf. legal regulation), it is important to consider the substantial differences between the two policies.

\section{Decriminalisation}

Two pertinent definitions of decriminalisation are:

- The removal of criminal sanctions for personal use and possession of limited quantities of a drug.

- De facto decriminalisation is the intentional ignoring of drug laws without changing them. A good example is employed in The Netherlands, where the possession and sale of cannabis are allowed despite the relevant laws remaining on the statute books.

Decriminalisation would certainly be preferable to the present SA situation, where the law criminalises people for drug use and possession. However, it is completely ineffective as a means of controlling the production, supply and purity of illegal drugs. As it also fails to address the fundamental reasons for the massive growth in the international criminal drug trade, decriminalisation is neither an effective nor distinct control model - it is simply a mild form of prohibition. ${ }^{[8]}$

Decriminalisation rarely provides for users to legally obtain their drugs, but implicitly directs them to continue sourcing drugs of unknown purity and potency. It also requires them to engage with criminals who sell their wares to anyone - including minors.

Although it does contribute to harm-reduction strategies relating to the drugs themselves, decriminalisation has a negligible effect on the criminal drug trade - at least as important a cause of drug-related medical and social ills as substance use itself. ${ }^{[9,10]}$

The prohibition-based drug laws implemented by 185 countries (including SA) that signed the 1961 United Nations Single Convention on Narcotic Drugs ${ }^{[11]}$ are primarily responsible for the disastrous failure by the international community to contain drug use and the concomitant multibillion dollar global trade in illicit drugs. ${ }^{[8,10]}$

Although this and its associated treaties allow countries to use their discretion as to how they structure their laws in relation to drug use, they specifically forbid the production and trade in those drugs deemed illicit by the United Nations (UN). Those countries, such as Portugal, that would prefer to go the legal regulation route are therefore having to make do with decriminalisation instead.

\section{Legal regulation - a proven, holistic and humanistic approach to the control of psychoactive drugs}

While legalisation is the process of making something illegal legal, legal regulation is the creation of a legal framework governing the production, supply and use of any drugs.

The term 'legal regulation' does not imply an unregulated free market model of drug control. Rather it involves the implementation of strict controls in a policy area where there are currently very few. Supporters of the status quo - i.e. prohibition - oppose the less punitive model of legal regulation as a radical drug policy strategy. However, historical evidence demonstrates that it is prohibition that is a (failed) radical policy.

The legal regulation of drug production, supply and use is far more in line with currently accepted ways of managing health and social risks in almost all other spheres of life such dangerous sports, road traffic accidents and sexually transmitted infections.

Any drug will be safer if its production and availability is regulated rather than left in the hands of criminals. This rationale applies to the riskier drugs too; drugs need to be regulated because they are dangerous, not because they are safe.

The laws governing alcohol and tobacco products can be found in variations of the legal regulation model that are operational in most countries. The abandonment of legal regulation (in favour of prohibition) of alcohol products in the USA in 1920, and its reintroduction 13 years later, is the most graphic demonstration that legal regulation of even a highly toxic psychoactive drug like alcohol is far better than its prohibition. ${ }^{[8,10]}$

Prohibition gifted a massive source of revenue to the criminal world. Contaminated alcohol products killed and maimed people, organised crime structures such as the Mafia became very powerful, and corruption among politicians, law enforcement structures and the judiciary rose dramatically. ${ }^{[10]}$ 
The UN conventions prohibiting psychoactive drugs such as heroin, cocaine, cannabis, methamphetamines, psychedelics and others have caused even more widespread damage and misery than did Prohibition in America. These outdated treaties were built on a foundation of wilful ignorance, fear, racism and the distortion of scientific evidence ${ }^{[10]}$ - influences that continue to prevail over contemporary scientific evidence, rationality and a humanistic approach to drug use. Unfortunately, most of the signatories of the UN treaties, including SA, continue to enforce their outdated, harmful and crime-friendly regulations.

It is to be hoped that its position statement ${ }^{[1]}$ is a signal that the CDA is moving away from being a laggardly government body that has been reluctant to take a lead in advocating the most basic harmreduction policies. It would be heartening to see SA take the bull by the horns and become a global leader in drug law reform.

Before it does that, it needs to accept a few fundamental realities:

- The 'war on drugs' has failed. The widespread use of drugs and the criminal edifice that controls the drug trade is not a result of legalising drugs, it is a result of criminalising them. ${ }^{[8-10,12,13]}$

- As humans have and always will seek out psychoactive substances, a drug-free society is unattainable. ${ }^{[14]}$

- The majority - over $80 \%$ - of people who use licit drugs or illicit drugs do not develop substance use disorders. ${ }^{[15-17]}$ Moreover, these casual users of drugs form the largest body of customers who drive both the legal and illegal drug trades.

- Most of the $<20 \%$ of people who do develop substance use disorders have significant psychosocial issues. ${ }^{[15,16]}$ They are the unfortunate ones whom the drug laws force onto the margins of society and into lives of crime. ${ }^{[10,13]}$

The CDA needs to take a wider look at the drug problem when drawing up its policies. Using confirmation bias to justify a drug such as cannabis's illegal status - without taking the harms of prohibition into account - is unworthy of a body that continually emphasises its commitment to evidence-based policies.

In spite of ample evidence supporting its use in the control of all psychoactive drugs, the SA drug laws only allow for the legal regulation of the two most harmful drugs, alcohol and tobacco. Moreover, the CDA recommends the legal status quo of prohibition for all others except cannabis, for which it now proposes decriminalisation in preference to legalisation. These confused positions are based neither on logic nor the considerable body of evidence supporting legal regulation.

The SA drug laws exacerbate rather than counter drug-related harms in several ways:

- Enable organised crime and gangsterism to flourish and (unintentionally) facilitate easy access by minors to illicit drugs. ${ }^{[13]}$
- Instead of helping drug users, they marginalise them and drive them into lives of crime. ${ }^{[10,13]}$

- Enforce the spraying of harmful herbicides on indigent, subsistence farmers' cannabis and food crops. ${ }^{[18]}$

- Trample on the human rights of adults who should be free to choose psychoactive drugs of their choice.

It is to be hoped that the next CDA position statement or NDMP will reflect a more scientific, evidence-based approach to the broader drug problem, as recommended by organisations such as the Global Commission on Drug Policy and the International Centre for Science in Drug Policy. ${ }^{[19,20]}$

\section{Keith Scott}

Simon's Town, Cape Town, South Africa

\section{Corresponding author: K Scott (zcottz@gmail.com)}

1. Stein DJ, for the Executive Committee of the Central Drug Authority. Position statement on cannabis. S Afr Med J 2016;106(6):569-570. DOI:10.7196/SAMJ.2016.v106i6.10863

2. Central Drug Authority of South Africa. The National Drug Master Plan 2013 - 2017. Pretoria: Department of Social Development, 4 July 2013.

3. Nutt DJ, King LA, Phillips LD, Independent Scientific Committee on Drugs. Drug harms in the UK: A multicriteria decision analysis. Lancet 2010;376(9752):1558-1565. DOI:10.1016/S01406736(10)61462-6

4. Lachenmeiera D, Rehm J. Comparative risk assessment of alcohol, tobacco, cannabis and other illicit drugs using the margin of exposure approach. Sci Rep 2015;5:8126. DOI:10.1038/srep08126

5. World Health Organization. Global Status Report on Alcohol and Health. Geneva: WHO, 2014

6. Calabria B, Degenhardt L, Hall W, Lynskey M. Does cannabis use increase the risk of death? 6. Calabria B, Degenhardt L, Hall W, Lynskey M. Does cannabis use increase the risk of death?
Systematic review of epidemiological evidence on adverse effects of cannabis use. Drug Alcohol Rev 2010:29(3):318-330. DOI:10.1111/j.1465-3362.2009.00149.x

7. Ksir C, Hart C. Cannabis and psychosis: A critical overview of the relationship. Curr Psychiatry Rep 2016;18(2):12. DOI:10.1007/s11920-015-0657-y

8. Taylor S, Buchanan J, Ayres T. Prohibition, privilege and the drug apartheid: The failure of drug policy reform to address the underlying fallacies of drug prohibition. Criminol Crim Justice 2016 (accessed 6 May 2016, online only). DOI:10.1177/1748895816633274

9. Nadelmann E. Drug prohibition in the United States: Costs, consequences, and alternatives. Science 1989;245(4921):939-947. DOI:10.1126/science.2772647

10. Hari J. Chasing the Scream: The First and Last Days of the War on Drugs. London: Bloomsbury, 2015.

11. United Nations. Single Convention on Narcotic Drugs. New York: UN, 1961.

12. Drucker E. Drug prohibition and public health: 25 years of evidence. Public Health Rep 1999;114(1):1429.

3. Goga K. The Drug Trade and Governance in Cape Town. Pretoria: Institute for Security Studies, 2014:263.

14. Crocq M. Historical and cultural aspects of man's relationship with addictive drugs. Dialogues Clin Neurosci 2007;9(4):355-361

15. Robins L, Helzer J, Davis D. Narcotic use in Southeast Asia and afterward: An interview Robins L, Helzer J, Davis D. Narcotic use in Southeast Asia and afterward: An interview
study of 898 Vietnam returnees. Arch Gen Psychiatry 1975;32(8):955-961. DOI:10.1001/ archpsyc. 1975.017602600190

16. Clarke H, Soneji N, Ko D, Yun L, Wijeysundera D. Rates and risk factors for prolonged opioid use after major surgery: Population based cohort study. BMJ 2014;348:g1251. DOI:10.1136/bmj.g1251

17. Mann J. British drugs survey 2014: Drug use is rising in the UK - but we're not addicted. The Guardian 5 October 2014

18. Fezisa M. War on dagga puts rural people at toxic risk. Mail and Guardian 19 March 2015.

19. Global Commission on Drug Policy. Taking Control: Pathways to Drug Policies that Work. Geneva: GCDP, 2014.

20. International Centre for Science in Drug Policy. Using Evidence to Talk about Cannabis. Toronto: ICSDP, 2015. http://www.icsdp.org/publications (accessed 6 May 2016).

S Afr Med J 2016;106(6):545-546. DOI:10.7196/SAMJ.2016.v106i6.11036 